

\section{Electrosynthesis of a Hyperbranched Dendrimeric Porphyrin Polymer. Optical and Electronic Characterization as Material for Bifunctional Electrochromic Supercapacitors.}

Javier E. Durantinia , Raul Rubio ${ }^{a}$, Claudia Solis ${ }^{a}$, Lorena Macora, Gustavo M. Morales ${ }^{a}$, Maria I. Mangione ${ }^{b}$, Daniel A. Heredia c, Edgardo N. Durantinic, Luis Otero*,a and Miguel

Gervaldo*,a.

a IITEMA Departamento de Química, Universidad Nacional de Río Cuarto-CONICET Agencia Postal Nro. 3, X5804BYA Río Cuarto, Córdoba, Argentina.

b IQUIR-CONICET, Facultad de Ciencias Bioquímicas y Farmacéuticas, Universidad Nacional de Rosario, Suipacha 531, S2002LRK Rosario, Argentina.

c IDAS Departamento de Química, Universidad Nacional de Río Cuarto-CONICET Agencia

Postal Nro. 3, X5804BYA Río Cuarto, Córdoba, Argentina.

* Corresponding authors.

E-mail address: mgervaldo@exa.unrc.edu.ar, 
E-mail address: lotero@exa.unrc.edu.ar

Keywords: Electropolymerization, Dendrimer, Porphyrin, Electrochromism, Supercapacitor. 


\begin{abstract}
A Zn (II) porphyrin monomer modified by four fully $\pi$-conjugated side-branches holding eight carbazole residues produces by electrochemical polymerization a hyperbranched polymeric conducting film. The polymer possesses electronic properties that confer to the film the capability for its application in energy storage devices as a supercapacitive material. This property is based on the pseudocapacitance generated by the reversible redox processes that can be induced in the organic polymeric film. The opened dendrimeric structure allows the formation of a sponge-like tridimensional arrangement, with large contact area between the liquid electrolyte and the film surface. The pseudocapacitive electrode material exhibits capacitances as high as $277 \mathrm{~F} \mathrm{~g}^{-1}$ at a current density of $4.5 \mathrm{~A} \mathrm{~g}^{-1}$, and presents a specific capacitance retention of $70 \%$ at $54.5 \mathrm{~A} \mathrm{~g}^{-1}$. This high capacitance retention demonstrates that the organic polymer could be used as a material for energy storage applications where a high discharge-recharge rate is needed. Also, the electrochromic behavior of the porphyrin polymer may be used in transparent devices where the charge discharge processes are followed by color changes.
\end{abstract}




\section{Introduction}

The synthesis, characterization and application of $\pi$-conjugated porous conducting polymers are of outmost importance in the development of organic-based functional materials. ${ }^{1,2}$ The formation of three-dimensional networks of covalent linked and conjugated building blocks allows to obtain an exceptional class of material, which possesses characteristics that are rarely obtained in other materials. ${ }^{3}$ Due to their open structure and high specific area that allows an appropriate diffusion and adequate interaction with other substances, $\pi$-conjugated porous conducting polymers have been applied in the development of sensors, ${ }^{4}$ catalytic materials, ${ }^{5}$ light absorbers, ${ }^{6}$ and energy storage devices such as batteries $^{7}$ and supercapacitors. ${ }^{8}$

For the construction of porous three-dimensional organic polymers the used building blocks must contain two or more reactive groups ${ }^{1}$ that allow an adequate coupling by chemical ${ }^{9-11}$ or electrochemical ${ }^{12,13}$ reactions. Thus, dendronized structures appear as ideal base units for the generation of porous organic frameworks. The hyperbranched dendrimeric polymers are formed by repetitive units that hold multiple branches arising from a core. ${ }^{14-16}$ Also, dendrimers possess highly monodisperse and well-defined three-dimensional structures that can contain an adequate porosity for molecular and/or ionic diffusion, encapsulation, and eventually reaction processes. Dendrimers can be precisely designed holding the adequate groups in order to get the desired functional material, including fully $\pi$-conjugated frameworks. ${ }^{14,15}$ Due to their particular characteristics, dendrimers have been used as component materials in different organic electronic devices, such as transistors, ${ }^{17}$ OLEDs ${ }^{17}$ and organic solar cells. ${ }^{18}$ In all these systems, it is important the contribution of the building blocks to the devices stability, which in the case of dendrimeric structures is supplied by the high glass-transition temperature that frequently exhibit these kind of materials. ${ }^{19}$ 
Tetrapyrrolic-based molecules and polymers are very important compounds due to their fundamental roles as light absorbers and redox centers in biologic systems, and also because of their numerous applications as components in practical devices, such as sensors, ${ }^{20}$ medical imaging, ${ }^{21}$ antibacterial systems, ${ }^{22,23}$ between others. Certainly, most of these applications are based on both, redox and light-absorbing properties of porphyrins ${ }^{24-26}$ and phthalocyanines. ${ }^{21,27}$ In several cases, the incorporation of tetrapyrrolic centers into conducting polymers is very convenient for device fabrication and application, because this confers an additional stability to the organic systems. ${ }^{28-30}$ There are several examples of porphyrin and phthalocyanine containing polymers obtained by chemical ${ }^{31-33}$ and electrochemical ${ }^{30,34}$ synthetic methodologies in both, in solution and as polymeric films. These materials have been successfully used as building blocks in a large variety of functional devices, ${ }^{20-23}$ including supercapacitors. ${ }^{35-37}$ In addition, the isolation of tetrapyrrolic centers in dendritic shells can modulate the photophysical, electrochemical, and chemical properties of the porphyrin in the polymer. ${ }^{38-40}$ Also, for the application of porphyrin containing dendrimers in electronic and/or optoelectronic devices, the dendrimer can hold $\pi$-conjugated branches, which provide electro/hole transport capability to the polymeric material. Likewise, other chromophores, as well as electron donor and/or electron acceptor moieties, and electrochemical active groups, can be introduced in the dendrimer branches as peripheral groups, which provide the wanted electronic or optoelectronic characteristics to the material. However, unfortunately in most of the cases dendrimer synthesis is difficult, expensive and time-consuming, ${ }^{41}$ often due to steric hindrance and solubility problems in the sequential synthesis steps. ${ }^{41}$ As a consequence, easier and more effective methods to encapsulate porphyrins preserving their functional properties afforded by dendritic shells are needed. In this sense, it is known the versatility of electrochemical synthesis methodologies for the generation of organic polymers as films over electrode surfaces that can be used as building blocks in the fabrication of functional devices. ${ }^{42-45}$ In the case of porphyrin derivatives, the electrochemical 
polymerization is usually carried out through the oxidative coupling of peripheral substituents, meanwhile the tetrapyrrolic macrocyclic ring remains unaltered. ${ }^{42,43}$ Thus, dendrimeric structures can be formed by the incorporation of specially designed electroactive branches to the porphyrin central core. It has been proved that hyper-branched fully $\pi$-conjugated dendritic macromolecules can be formed by electrochemical synthesis from the appropriate dendrimeric monomers. ${ }^{14,46,47}$ Also, it is important to mention that the electropolymerization methodology towards the generation of films for supercapacitors has become an emerging matter in the last years. ${ }^{48,49}$

In Zn (II) porphyrin monomer (PD, Figure 1c), the chromophore (P, Figure 1a) was modified by four fully $\pi$-conjugated side-branches (D, Figure 1b). The branches have 2,3,5,6-tetraflourphenyl fused to 1,2,3-triazole moieties and triphenyl amine (TPA) fused to two carbazole (CBZ) residues. Both carbazoles in each arm can also undergo the well-known electrochemical initiated radical coupling ${ }^{15,47}$ that promotes the formation of a hyperbranched open fully conjugated structure. Moreover, triazole modified Zn (II) porphyrins can form coordination assemblies involving the triazole moieties with the Zinc (II) centers of other porphyrins. ${ }^{50-53}$ This avoids $\pi$ staking between polymeric chains, contributing in the obtainment of an open structure in the polymer and allowing ionic diffusion. The electrogenerated polymer possesses electronic properties that confer to the material the capability for its application in electrochromic and energy storage devices. The reversible oxidation-reduction of the polymer leads to evident color changes in the thin film that can be seen by the naked eye. Zhang and col. reported the construction and characterization of versatile stimulus-responsive micro-supercapacitor with reversible electrochromic window. ${ }^{54}$ Also, the use of $2 \mathrm{D}$ soft nanomaterials is an emerging technology for the development of micro-supercapacitors with ultra-high volumetric power density. ${ }^{55-58}$ In our case, specific capacitances as high as $277 \mathrm{~F} \mathrm{~g}^{-1}$ at a current density of $4.5 \mathrm{~A} \mathrm{~g}^{-1}$ were measured. This last property is based on the pseudocapacitance generated by the oxidation-reduction reactions that can be induced in the 
conducting dendrimeric film. The presence of numerous reversible redox centers in porous electrode materials is essential for the occurrence of pseudocapacitive processes. ${ }^{59,60}$ Consequently, the capacitance retention and the electrochromic behavior of the porphyrin polymeric film demonstrate that the material could be used in combined energy storage devices where the charge-discharge processes can be followed by color changes. ${ }^{54,61}$ 


\section{Experimental section}

\subsection{Materials}

Tetrabutylammonium hexafluorophosphate $\left(\mathrm{TBAPF}_{6}\right)$ and Tetrabutylammonium Perchlorate (TBAP) were purchased from Sigma Aldrich. 1,2-Dichloroethane (DCE) was purified by distillation with $\mathrm{CaH}_{2}\left(50 \mathrm{~g} \mathrm{~L}^{-1}\right)$ as the water removal agent. Anhydrous acetonitrile (ACN) was purchased from Sigma Aldrich. All the other chemical reagents were used as received. The indium tin oxide (ITO) coated glass substrates (Delta Technologies, nominal resistance 8-12 $\Omega /$ square) were cleaned in an ultrasonic bath with toluene, acetone, ethanol and deionized water, respectively, and then dried with nitrogen.

PD was obtained from zinc(II) 5,10,15,20-tetrakis(2,3,5,6-tetrafluoro-4-azidophenyl)porphyrin and $(E)-N, N$-bis(4-(9H-carbazol-9-yl)phenyl)-4-(4-ethynylstyryl)aniline by click chemistry, according with the procedure previously reported. ${ }^{62}$ Briefly, the alkyne compound and the azidophenyl derivative were dissolved in a mixture of tetrahydrofuran and acetonitrile under argon atmosphere. Then, $\mathrm{CuI}$ and $\mathrm{N}, \mathrm{N}$-diisopropylethylamine were added and the reaction mixture was heated to $60{ }^{\circ} \mathrm{C}$ and stirred for $16 \mathrm{~h}$. Solvents were concentrated under vacuum and the crude product was purified by flash chromatography (hexane:dichlorometane) to yield the corresponding PD. P was obtained from zinc(II) 5,10,15,20tetrakis(2,3,5,6-tetrafluoro-4-azidophenyl)porphyrin and phenylacetylene, while D was synthesized from (E)-N,N-bis(4-(9H-carbazol-9-yl)phenyl)-4-(4-ethynylstyryl)aniline and phenylazide, following the approach described for PD.

\subsection{Instrumentation and Measurements}

UV-Vis absorption spectra were recorded on a diode array spectrophotometer (Agilent HewlettPackard, HP 8452A) in $1 \mathrm{~cm}$ cuvettes at room temperature. Cyclic voltammetry measurements of the 
monomers and films were performed in a potentiostat-galvanostat Autolab (Electrochemical Instruments), using a one-compartment cell equipped with a Pt $\left(0.204 \mathrm{~cm}^{2}\right)$ or ITO $\left(1.2 \mathrm{~cm}^{2}\right)$ working electrodes, a Pt loop as counter electrode and a silver wire quasi-reference electrode. Additionally, in each experiment, the reference electrode potential was monitored using ferrocene as a standard, and the potential axis was calibrated against the formal potential for the saturated calomel electrode (SCE). When large area ITO electrodes were used, the counter electrode was isolated from the monomer solution by a glass frit in order to avoid interference with the redox reactions occurring at the working electrode. Electrochemical studies of $0.5 \mathrm{mM}$ of monomers were carried out in DCE deoxygenated solution (nitrogen bubbling), with 0.10 $\mathrm{M} \mathrm{TBAPF}_{6}$ as supporting electrolyte. The electrochemical responses of the electropolymerized films were carried out in DCE deoxygenated solution (nitrogen bubbling), with $0.10 \mathrm{M} \mathrm{TBAPF}_{6}$ as supporting electrolyte. In all the electrochemical measurements the Pt working electrode was mechanically cleaned between experiments by polishing with $0.3 \mu \mathrm{m}$ alumina paste followed by solvent rinses.

Spectroelectrochemical experiments were carried out in a custom cell built from a commercial UV-Visible cuvette. ITO-coated glass, Pt and an Ag wire were used as working, counter and reference electrode respectively. The cell was placed in the optical path of the sample light beam. The background correction was obtained by taking an UV-Vis spectrum of a blank cell (an electrochemical cell with an ITO working electrode without the film) with identical conditions to those of the polymer film experiment.

AFM measurements were carried out on an Agilent 5500 SPM microscope (Agilent Technologies, Inc.) working in acoustic AC mode and equipped with a $8 \mu \mathrm{m}$ x $8 \mu \mathrm{m}$ scanner, using aluminum backsidecoated silicon probes (MikroMasch, HQ:NSC14/AL BS) with a typical tip radius of $\sim 8 \mathrm{~nm}$ and a spring constant $\sim 5 \mathrm{~N} \mathrm{~m}^{-1}$, vibrating just under their fundamental resonance frequency $(\sim 160 \mathrm{kHz})$. The film thicknesses were measured using the scratch-and-scan method, which consists in the mechanical removal of a sharp line of the film and subsequent imaging of the surface by AFM. Electrodes were washed with 
solvent to remove remaining electrolyte and low-weight molecular species before use. The experiments were realized in stationary dry-air atmosphere and the raw data were processed with the software Gwyddion. Scanning electron microscopy (SEM) images were performed with a field emission scanning electron microscope FE-SEM, Sigma Zeiss with an acceleration voltage of $5 \mathrm{kV}$.

The supercapacitor charging-discharging experiments were achieved with chronopotentiometry method in a three-electrode configuration using a large area ITO working electrode $\left(1.2 \mathrm{~cm}^{2}\right)$, a Pt foil as counter electrode and a silver quasi-reference electrode, in ACN solution containing 0.10 M TBAP. After polymeric film formation by continuous polymerization cycles in DCE $(0.10 \mathrm{M}$ TBAPF 6 ), the electrodes were taken out from the monomeric solution, gently rinsed with pure DCE to remove any residue of unreacted monomer and/or electrolyte, washed three times by immersion in ACN and placed in a solution containing only ACN-supporting electrolyte (TBAP). Before charge-discharge experiments, voltammetric oxidation-reduction cycles were applied to the PD-film in this media until repetitive profiles were achieved (usually five cycles were enough, ten cycles were used as a standard).

The gravimetric capacitance was evaluated from the slopes of the discharge curves in chargedischarge experiments ${ }^{63,64}$ using the equation: $\mathrm{C}=\mathrm{I} /(\mathrm{dV} / \mathrm{dt})$, where $\mathrm{I}$ is the discharging current per mass unit applied to the electrode, and $\mathrm{dV} / \mathrm{dt}$ is the slope during the voltage drop in the galvanostatic chargedischarge experiments.

Electrochemical impedance spectroscopy (EIS) was performed in a three electrode cell configuration using the Frequency Response Analyzer module of a PGSTAT 30 Autolab potentiostat in the range between 0.1 to $10^{5} \mathrm{~Hz}$ with a perturbation amplitude of $5 \mathrm{mV}$ at an applied potential of $1.1 \mathrm{~V} .{ }^{65,66}$ The amount of electropolymerized material over the ITO electrode was estimated following the methodology reported by $\mathrm{Ma},{ }^{35}$ where it was supposed that after electropolymerization the change in the absorption coefficient of porphyrin chromophore was negligible. 


\section{Results and discussion}

\subsection{Electrochemistry}

Electrochemical studies were carried out in order to know the electrochemical properties of $\mathbf{P}, \mathbf{D}$, and PD and also to check the formation of polymeric films. Figure 2a-c shows anodic scans at different inversion potentials for the three molecules. P shows the typical two oxidations waves at 1.13 and $1.48 \mathrm{~V}$, which are related to the formation of the radical cation and dication respectively of the porphyrin macrocycle. ${ }^{67}$ Triazole moieties are not oxidized in the scan range, in agreement with already reported results for structural related compounds. ${ }^{52} \mathbf{D}$ presents three oxidation processes at $0.71,1.09$, and $1.39 \mathrm{~V}$, being the second and third ones not completely reversible. The first peak is reversible and assigned to the formation of a stable triphenylamine (TPA) radical cation. The second and third peaks are attributed to the formation of carbazole $(\mathrm{CBZ})$ radical cations that occur at different oxidation potentials, due to the proximity of both oxidizable CBZ groups. ${ }^{15}$ The electrochemical behavior of $\mathbf{D}$ is very similar to that observed before in structural related molecules formed by TPA cores substituted with CBZ groups. ${ }^{14-16}$ PD exhibits several oxidation peaks that occur at similar potential values than those observed for $\mathbf{P}$ and D. Because of the close proximity in the redox potentials of PD, it is difficult to correlate each peak with the different electroactive groups present in PD. ${ }^{68}$ In order make a better assignment of the peaks, DPV scans were performed for the three studied molecules (Figure 2d). P presents two oxidation peaks, while D presents three oxidation waves, the first two oxidation occurring at lower potentials than those observed for $\mathbf{P}$, in fully agreement with cyclic voltammetry results. On the other hand, PD presents four oxidation peaks that appear at potential values similar to the ones detected for $\mathbf{P}$ and $\mathbf{D}$. It is also observed from the DPV scans that the electrochemical behavior of PD seems to be formed by a combination of the $\mathbf{P}$ and $\mathbf{D}$ electrochemical redox systems. According to the DPV scan of PD, it could be possible to assign the oxidation peaks to the formation of TPA radical cations (first peak), P radical cations (second peak), CBZ 
radical cations (third peak), and the last one to the formation of $\mathbf{P}$ dications as well as to the formation of the second $\mathrm{CBZ}$ radical cations that occurs at higher potentials.

Figure 3a,b shows ten anodic scans of $\mathbf{D}$ and $\mathbf{P D}$ in the same potential range. As it can be seen, $\mathbf{D}$ and PD present a progressive growth in the oxidation-reduction currents with every new cycle, indicating the deposition of an electroactive film over the electrode surface. On the contrary, cycling of $\mathbf{P}$ in the same potential range does not produce any increases in the oxidation/reduction currents, because of the lack of electropolymerizable groups (no CBZ units present). After ten continuous cycles the electrodes were removed from the respective monomeric solutions and placed in a solution containing only supporting electrolyte. D-film presents an electrochemical response which is characterized by a bell shaped oxidation peak at $0.87 \mathrm{~V}$ and a second oxidation wave (that is not well defined) at around 1.35 V (Figure 3c). PDfilm presents also two oxidation peaks $(0.85$ and $1.25 \mathrm{~V})$, although the second oxidation peak is more defined and also presents a bigger oxidation peak compared to D-film (Figure 3d). This second oxidation peak is related to the second oxidation process observed in D-film and to the oxidation of the porphyrin macrocycle. Moreover, both films present a linear relation between the peak oxidation currents and the scan rate, which confirms the electrodeposition of an electroactive film on the electrode.

The similarity between the electrochemical responses of both films could be attributed to the generation of analogous polymeric films, which present dicarbazole units (DCBZ) as building blocks. The CBZ units present in both monomers are oxidized generating unstable radical cations, reacting and forming DCBZ. ${ }^{69} \mathrm{DCBZ}$ containing polymers commonly present two oxidation peaks that are associated to the formation of radical cation and dication of DCBZ units. ${ }^{70,71}$ Therefore, the oxidation peaks observed for D-film are related to oxidation of the TPA and DCBZ units, while the bigger current observed in the second oxidation peak of PD-film could be related to oxidation of the DCBZ units and also to the oxidation of the porphyrin macrocycle. Thus, for the electrochemical synthesis of the PD-films we used in a 
conventional electrochemical cell a solution of the $\mathrm{Zn}$ (II) porphyrin monomer, which possesses four fully $\pi$-conjugated side-branches ending each one in two CBZ residues. After electrochemical oxidation of the monomer, the oxidized CBZ moieties undergo the well-known radical cation coupling (see Scheme S1) forming dicarbazole units. Because of the fact that each monomer holds eight CBZ ending groups, a hyperbranched material is formed. This material is adsorbed over the electrode surface (Pt or ITO) and remains as a conducting thin film, with an extended $\pi$-conjugation. Due to the adequate electric conductivity of the film, in the successive CV cycles more CBZ radical cations are formed (both in the ending branches of the deposited material and in the monomers in solution). The coupling between these radical cations generated a continuous increment in the amount of the deposited material and, as a consequence, in the film thickness. The coupling mechanism and the consequent polymer growing are depicted in Schemes $\mathbf{S 1}$ and $\mathbf{S 2}$.

\subsection{Spectroelectrochemical and Microscopical Characterization of D and PD films}

In order to confirm the film formations, to study their electro-optical properties and to analyze the reversibility associated with the redox processes, both films were generated over semitransparent ITO electrodes. Figure 4a shows repetitive cyclic voltammograms of PD (over ITO), where increases in the oxidation/reduction currents are observed with each new cycle. The electrochemical response of PD-film in DCE presents two redox processes, with oxidation and reduction peak currents that are linear with the scan rate (Figures $4 \mathbf{b}, \mathbf{c}$ ). As it can be observed, both, film growing and its corresponding electrochemical response are similar to the obtained in Pt electrode. Also, the PD-film is stable upon oxidation-reduction cycling, which is demonstrated by the similarities between the fifth, tenth and fiftieth cyclic voltammograms (Figure 4d). In addition, for $\mathbf{D}$ molecule, the film formation and its electrochemical response in DCE solution over ITO are similar to those observed in Pt electrodes. The absorption spectra of the films obtained at an applied potential of $-0.20 \mathrm{~V}$ (reduced state) were subtracted from the absorption 
spectra obtained at the different applied potentials and plotted as $\Delta$ Abs (Figure 5a,b). Also, the principal absorption maximum wavelength traces were plotted as function of the applied potential (Figure 5c,d). The absorption spectrum of D-film at $-0.20 \mathrm{~V}$ (inset Figure 5a) presents an absorption band at $335 \mathrm{~nm}$, which is related to $\pi-\pi$ transition of the DCBZ and TPA units. At potentials between $0.60 \mathrm{~V}$ and the first oxidation peak, the band at $335 \mathrm{~nm}$ is bleached and a new positive band with a maxima at $425 \mathrm{~nm}$, that also extends to the IR region, appears (Figure 5a). The bands at 335, $425 \mathrm{~nm}$, and the one in the IR, all change in the same potential ranges, indicating that they are related to the same redox system. At the foot of the second oxidation wave the band at $335 \mathrm{~nm}$ is still bleached, the band at $425 \mathrm{~nm}$ decreases and a new band at $750 \mathrm{~nm}$ starts growing. At more anodic potentials the band at $750 \mathrm{~nm}$ keeps growing and reaches its maximum value at $1.70 \mathrm{~V}$. The changes in the principal absorption traces follow the voltammetric response of D-film (Figure 5c). The $335 \mathrm{~nm}$ trace (related to neutral DCBZ) starts decreasing while the $425 \mathrm{~nm}$ trace (related to DCBZ radical cation) grows at the foot of the first oxidation peak, and is maxima at the potential of the first oxidation peak. Then the traces at 750 and $950 \mathrm{~nm}$ (related to DCBZ dication) are increased while the $425 \mathrm{~nm}$ is decreased during the second oxidation process. When the film is completely oxidized $(1.70 \mathrm{~V})$ the $750 \mathrm{~nm}$ trace is maxima and the $425 \mathrm{~nm}$ trace is minimum.

The spectrum of PD-film at $-0.20 \mathrm{~V}$ (inset Figure 5b) shows a band at $325 \mathrm{~nm}$ attributed to $\pi-\pi$ transition of the DCBZ and TPA units, ${ }^{47}$ the Soret band at $422 \mathrm{~nm}$, and the Q bands commonly observed in Zn (II) substituted porphyrins. ${ }^{72,73}$ PD-film presents similar changes in the absorption spectra as well as in the principal absorption maximum wavelengths to those observed for D-film at different applied potentials (Figure 5b,d). The band at $325 \mathrm{~nm}$ (related to neutral DCBZ) starts to be bleached and a new band at $390 \mathrm{~nm}$ (related to DCBZ radical cation) that extends to the IR appears at the foot of the first oxidation peak and these bands keep changing until the first oxidation peak is reached. At the beginning of the second oxidation peak $(1.10 \mathrm{~V})$ the band at $422 \mathrm{~nm}$ as well as the Q band $(550 \mathrm{~nm})$; both related to 
the porphyrin macrocycle, are bleached; indicating that the macrocycle is oxidized at these potential values. A new broad band between 580 and $1000 \mathrm{~nm}$ (related to DCBZ dication) appears at the second oxidation potential. This broad band also presents the development of a band at $695 \mathrm{~nm}$, which is related to the formation of the porphyrin radical cation (Figure 5b). Figure 5d shows the changes in the selected wavelength traces at different applied potentials. The trace at $325 \mathrm{~nm}$ (related to neutral DCBZ) decreases while the $425 \mathrm{~nm}$ trace (related to DCBZ radical cation) increases a little bit during the first oxidation process. Then, the traces at 425 and $695 \mathrm{~nm}$ start both changing at the foot of the second oxidation wave; the $425 \mathrm{~nm}$ trace decreases because of the bleaching of the porphyrin Soret band, and the $695 \mathrm{~nm}$ trace (associated to the porphyrin radical cation) increases. These traces keep changing in the range of the second oxidation process (Figure 5d). The changes observed in absorption spectra during anodic oxidation of PD-film conduct to changes in the colors of the film (Figure 6). The film shows four different colorations that can be seen by the naked eye, conferring to the material reversible electrochromic properties. Depending on the oxidation state, the film presents a light brown (neutral state), light orange (oxidized state), green (semi-oxidized state), and blue (fully oxidized state) colors.

Both, the electrochemical and spectroelectrochemical data indicate the presence of DCBZ units in D-film and PD-film. DCBZ based polymeric films commonly present two oxidation peaks and show an absorption band at $430 \mathrm{~nm}$ (that extend to IR) during the first oxidation process, and also a band at 750 $\mathrm{nm}$ in the second oxidation process, being these bands attributed to the formation of the corresponding radical cation and dication of DCBZ units. ${ }^{47}$ Also, Zn (II) substituted Porphyrins are oxidized forming radical cations, which commonly present an absorption band at around $700 \mathrm{~nm} .{ }^{73} \mathrm{~A}$ band at a similar wavelength was observed during the second oxidation of the PD-film, being possible to attribute this band to the formation of the radical cation of the macrocycle. D-film and PD-film are both reversibly oxidized and reduced. This reversibility is confirmed by the fact that the traces in the forward and backward scan 
match the shape of the corresponding film electrochemical response. Also, the traces reach their initial values at the end of the CV scan, being nearly mirror images the behaviors of the traces in the forward and backward scans. Consequently, due to the formation of Dicarbazole units, the $\pi$-conjugation between monomers is effective. Dicarbazole radical cations and dications generated during PD-film oxidation are stable due to the extended conjugation. ${ }^{15,47}$ On the other hand, the degree of orbital overlapping in the monomer arms, and between the arms and the porphyrin central core is affected by the twisted geometry of the dendrimeric molecule. However, the electrochemical and spectroelectrochemical results demonstrated that the PD-film is suitable for charge transport. In this sense, it should be noted that in other structural related porphyrin based polymers, ${ }^{13,35,74}$ the film conductivity indicated that the conjugation is suitable for hole transport.

To investigate the morphological properties of D-film and PD-film, SEM images were obtained. Figure 7a,b shows representative images of D-film and PD-film respectively. The morphology of both films is very different. D-film presents an even and nearly smooth surface formed by a compact agglomeration of fused spherical particles of about 50-100 nm. On the contrary, PD-film seems to consist of small spherical particles that are connected one to the other forming a fiber network that generates a sponge-like tridimensional structure leaving void spaces. The void spaces into the film can generate large contact areas between the liquid electrolyte and the film surface. Also, this porous structure could form pathways for adequate ion diffusion and migration.

To further investigate the surface morphology of PD-film AFM, images of films with different thicknesses were taken. The different film thicknesses were obtained by changing the number of polymerization cycles. Figure S1 a,b shows that the film absorbance and the film electro-oxidation charge change linearly with the number of polymerization cycles in the analyzed range. Also, Figure S1c shows that the film thickness (measured by AFM) and the polymer mass hold a linear relationship. It can be seen 
in Figure 8a that for the thinner film (two polymerization cycles), the polymer surface is very homogenous, fully covering the electrode and presenting a similar height, with a film thickness of about $35 \mathrm{~nm}$. When the thickness is increased (four polymerization cycles), taller regions star to appear and the surface becomes inhomogeneous. The height distribution changes a lot, and the thickness scales to $70 \mathrm{~nm}$ (Figure 8b). After seventeen polymerization cycles the surface presents a height distribution that changes from nanometers to values close to micron scale. The electrode surface is now covered completely with polymeric regions of different heights (Figure 8c).

\subsection{PD-film Galvanostatic Charge-Discharge (GCD) tests}

Due to the reversible oxidation-reduction processes that the dendronized polymeric film undergoes, it is expected that the pseudo-capacitive behavior would make the polymer adequate for their use as an active material in supecapacitor device construction. However, due to the high resistance of the DCE solvent-electrolyte system we analyzed the electrochemical response and stability of the polymeric film in ACN containing 0.10 M TBAP. As it is shown in Figure 9a, the PD-film formed over a large surface ITO electrode $\left(\sim 1.2 \mathrm{~cm}^{2}\right)$ by ten polymerization cycles also presents a reversible electrochemical response that is characterized by two well defined reversible redox processes, which involve oxidation of the central Zn (II) porphyrin cores, the triphenyl amine and dicarbazole residues in the dendrimeric arms. Moreover, the anodic and cathodic current peaks exhibit a linear relationship with the voltammetric scan rate (Figure 9b). This fact demonstrates that the surface confined redox reactions hold adequate reversibility and fast kinetics in ACN-TBAP related to the charge transfer processes, both necessary characteristics for the generation of pseudocapacitive energy storage occurrence. Additionally, the film is stable upon several oxidation-reduction cycles, as it is evidenced in Figure 9a where the first, fifteenth and fiftieth cycles are superimposed and almost no difference is observed, showing null or very low polymer degradation. It is also expected that, considering the open tridimensional structure of the film, 
the necessary ionic migration and diffusion are allowed into the polymeric conducting film. In order to evaluate the performance of the PD-film as supercapacitive material, galvanostatic charge-discharge experiments at different current densities were conducted in a three electrode setup (ACN $0.10 \mathrm{M}$ TBAP). ${ }^{75,76}$ The onset and cutoff potentials are similar to those displayed in the cyclic voltammetry experiments. In the potential range between $0.00-0.80 \mathrm{~V}$, the voltage rises vertically, and the energy stored in this range, originated in the contribution of the electronic double-layer capacitance, is negligible. ${ }^{77,78}$ In contrast, the responses exhibit a quasi-triangular charge-discharge behavior at different density currents in the 0.80 to $1.30 \mathrm{~V}$ range (Figure 10a), originated in the pseudocapacitance associated to the reversible redox processes that occur in the polymeric material. The discharge and charge curves are nearly mirror images, indicating fast and reversible electron exchange. The small deviation of the triangular form in the GCD curves is originated in the pseudocapacitive origin of the observed phenomenom. ${ }^{79}$ Also, the chargedischarge curves show good stability at different current densities. Figure 10b exhibits the capacitance retention after different galvanostatic charge-discharge cycles (18.2 $\mathrm{A} \mathrm{g}^{-1}$, see inset) showing that the material has good recyclability, in agreement with the reversibility observed by cyclic voltammetry (Figure 9a) and spectroelectrochemical experiments (Figure 5d). After 3000 cycles PD-film presents a capacitance retention close to $80 \%$. Based on the discharge curves, PD-film shows a maxima specific capacitance of $277 \mathrm{~F} \mathrm{~g}^{-1}$ at a current density of $4.5 \mathrm{~A} \mathrm{~g}^{-1}$. This value is lower than the reported for hydrogenbonded metal porphyrin frameworks based supercapacitors, ${ }^{36}$ but comparable to the values informed for electrogenerated porphyrin polymers ${ }^{35}$ and to a porphyrin/polypyrrole hybrid material. ${ }^{37}$ As the current density increases, the charge and discharge times are significantly shortened, but it should be noted that at current regimes as high as $54.5 \mathrm{~A} \mathrm{~g}^{-1}$, the film presents a specific capacitance retention of $70 \%(193.9$ $\mathrm{F} \mathrm{g}^{-1}$ ) (Figure 10c). Taking $0.5 \mathrm{~V}$ as the potential window $\left(\mathrm{V}_{0}\right)$ at a current density of $4.5 \mathrm{~A} \mathrm{~g}^{-1}$, an Energy density $\left(\mathrm{E}_{\mathrm{D}}\right)$ of $9.5 \mathrm{Wh} \mathrm{kg}^{-1}$ and Power density $\left(\mathrm{P}_{\mathrm{D}}\right) 1.4 \mathrm{KW} \mathrm{kg}{ }^{-1}$ can be estimated. ${ }^{63,64}$ Electrochemical 
impedance spectroscopy (EIS) was carried out in order to further analyze the electrochemical behavior of the polymeric material. Figure 10d shows the obtained Nyquist plot for a thin film electrode generated as the one showed in Figure 4a. The experimental data were fitted with the Randles equivalent circuit showed as an inset in Figure 10d using the software EIS Spectrum Analyzer. The circuit consists of an ohmic resistance $\left(\mathrm{R}_{\mathrm{ES}}\right)$, an interfacial charge transfer resistance $\mathrm{R}_{\mathrm{CT}}$, and two constant phase elements: $\mathrm{C}_{\mathrm{DL}}$ representing and electric double-layer capacitance and $\mathrm{C}_{\mathrm{PS}}$ representing the pseudocapacitance of the electrode. ${ }^{65,66}$ The diffusion controlled process into the electrode was fitted with a Warburg element $Z_{\mathrm{w}}$. The plot exhibit two regions, the first at high-frequency (inset Figure 10d) shows a semicircle with intercept at the real axis at $34.1 \Omega$, which represents the equivalent series resistance $\left(\mathrm{R}_{\mathrm{ES}}\right)$ originated in the ionic resistance of the electrolyte, electronic resistance of the electrode and contacts. The diameter of the semicircle is $11.6 \Omega$, which is associated to faradaic charge transfer resistance at the electrode/electrolyte interface $\left(\mathrm{R}_{\mathrm{CT}}\right)$. At low frequency the second region in the Nyquist plot shows a nearly vertical line indicating capacitive behavior of the electrode. ${ }^{65,66}$ The gravimetric capacitance obtained from the fitted data was $258 \mathrm{~F} \mathrm{~g}^{-1}$, which is comparable with the value calculated from chargedischarge experiments. The low charge transfer resistance is in agreement with the fast redox process observed in the polymeric material. ${ }^{65,66}$

This high capacitance retention demonstrates that the PD-film can be used as a material for energy storage applications where a high discharge-recharge rate is needed. ${ }^{80}$ It is proposed that this remarkable specific capacitance and charge-discharge stability is due to the highly crosslinked and hyperbranched open structure of the polymeric skeleton. The structure promotes the redox activity of the electrochemical active centers in the material, and the concomitant electronic and ionic transportation through the fully conjugated polymer chains and the porous structure. This also allows fast and reversible redox processes that contribute to the observed pseudocapacitive effect. Figure 11 shows an idealized spatial arrangement 
of nine monomers obtained by simple molecular mechanic calculation that allow the appreciation of the void spaces into the polymeric structure. This proposed structure is originated by the coupling of the electrochemically generated peripheral CBZ radical cations, forming DCBZ units whose presence was confirmed by the electrochemical and spectroelectrochemical experiments. 


\section{Conclusions}

A porphyrin polymeric film was generated by electrochemical polymerization, using a carbazole functionalized porphyrin monomer. The electrogenerated polymeric film is formed by dendronized porphyrins connected by DCBZ and presents a fully hyperbranched $\pi$-conjugate system. The presence of DCBZ units in the polymer is confirmed by electrochemical and spectroelectrochemical studies. The polymeric film possesses a sponge-like tridimensional structure formed by small spherical particles connected one to the other leaving void spaces. This structure generates a large contact area between the liquid electrolyte and the film surface, and also forms pathways for an adequate ion diffusion and migration. The dendronized polymeric film showed reversible oxidation-reduction processes that involved the porphyrin core, the triphenyl amine and dicarbazole residues. Because of the electrochemical reversibility and the open tridimensional structure of the film, it was tested as pseudocapacitive material. The pseudocapacitive electrode material exhibited capacitances as high as $277 \mathrm{~F} \mathrm{~g}^{-1}$ at a current density of $4.5 \mathrm{~A} \mathrm{~g} \mathrm{~g}^{-1}$, and presented a specific capacitance retention of $70 \%\left(193.9 \mathrm{~F} \mathrm{~g}^{-1}\right)$ at $54.5 \mathrm{~A} \mathrm{~g}^{-1}$. This high capacitance retention demonstrates that the PD-film could be used as a material for energy storage applications where a high discharge-recharge rate is needed. Also, the electrochromic behavior of the porphyrin polymer may be used in transparent devices where the charge discharge processes are followed by color changes.

\section{Acknowledgements}

Authors are grateful to Secretaría de Ciencia y Técnica, Universidad Nacional de Río Cuarto (SecytUNRC), Consejo Nacional de Investigaciones Científicas y Técnicas (CONICET) and Agencia Nacional de Promoción Científica y Tecnológica (ANPCYT) of Argentina for financial support. 


\section{References}

1. Y. Xu, S. Jin, H. Xu, A. Nagai, D. Jiang, Chem. Soc. Rev., 2013, 42, 8012-8031.

2. Q. Chen, B.-H. Han, Macromol. Rapid Commun., 2018, 39, 1800040.

3. C. Gu, N. Huang, Y. Chen, L. Qin, H. Xu, S. Zhang, F. Li, Y. Ma, D. Jiang, Angew. Chem. Int. Ed., 2015, 54, 13594-13598.

4. S.-C. Luo, J.L. Thomas, H.-Z. Guo, W.-T. Liao, M.-H. Lee, H.-Y. Lin, ChemistrySelect, 2017, 2 , 79357939.

5. R. Palkovits, M. Antonietti, P. Kuhn, A. Thomas, F. Schüth, Angew. Chem. Int. Ed., 2009, 48, 69096912.

6. L. Chen, Y. Honsho, S. Seki, D. Jiang, J. Am. Chem. Soc., 2010, 132, 6742-6748.

7. S. Zhang, W. Huang, P. Hu, C. Huang, C. Shang, C. Zhang, R. Yang, G. Cui, J. Mater. Chem. A, 2015, 3, 1896-1901.

8. Y. Guo, W. Li, H. Yu, D.F. Perepichka, H. Meng, Adv. Energy Mater., 2017, 7, 1601623.

9. J.-X. Jiang, F. Su, A. Trewin, C.D. Wood, H. Niu, J.T.A. Jones, Y.Z. Khimyak, A.I. Cooper, J. Am. Chem. Soc., 2008, 130, 7710-7720.

10. G. Cheng, T. Hasell, A. Trewin, D.J. Adams, A.I. Cooper, Angew. Chem. Int. Ed., 2012, 51, $12727-$ 12731.

11. J.-X. Jiang, A. Trewin, D.J. Adams, A.I. Cooper, Chem. Sci., 2011, 2, 1777-1781.

12. J. Durantini, M.B. Suarez, M. Santo, E. Durantini, T. Dittrich, L. Otero, M. Gervaldo, J. Phys. Chem. C, 2015, 119, 4044-4051.

13. J. Durantini, G.M. Morales, M. Santo, M. Funes, E.N. Durantini, F. Fungo, T. Dittrich, L. Otero, M. Gervaldo, Org. Electron., 2012, 13, 604-614. 
14. M.I. Mangione, R.A. Spanevello, A. Rumbero, D. Heredia, G. Marzari, L. Fernandez, L. Otero, F. Fungo, Macromolecules, 2013, 46, 4754-4763.

15. M.I. Mangione, R.A. Spanevello, D. Minudri, P. Cavallo, L. Otero, F. Fungo, Electrochim. Acta, 2018, 263, 585-595.

16. M.I. Mangione, R.A. Spanevello, D. Minudri, D. Heredia, L. Fernandez, L. Otero, F. Fungo, Electrochim. Acta, 2016, 207, 143-151.

17. M. Ullah, K. Tandy, A.J. Clulow, P.L. Burn, I.R. Gentle, P. Meredith, S.-C. Lo, E.B. Namdas, ACS Photonics, 2017, 4, 754-760.

18. D.M. Stoltzfus, C.-Q. Ma, R.C.R. Nagiri, A.J. Clulow, P. Bäuerle, P.L. Burn, I.R. Gentle, P. Meredith, Appl. Phys. Lett, 2016, 109, 103302.

19. J. You, G. Li, Z. Wang, Polymer, 2012, 53, 5116-5123.

20. D. Vlascici, N. Plesu, G. Fagadar-Cosma, A. Lascu, M. Petric, M. Crisan, A. Belean, E. FagadarCosma, Sensors, 2018, 18, 2297.

21. M. Imran, M. Ramzan, A.K. Qureshi, M.A. Khan, M. Tariq, Biosensors, 2018, 8, 95.

22. L. Chen, H. Bai, J.-F. Xu, S. Wang, X. Zhang, ACS Appl. Mater. Interfaces, 2017, 9, 13950-13957.

23. M.B. Ballatore, J. Durantini, N.S. Gsponer, M.B. Suarez, M. Gervaldo, L. Otero, M.B. Spesia, M.E. Milanesio, E.N. Durantini, Environ. Sci. Technol., 2015, 49, 7456-7463.

24. C.W. Leishman, J.L. McHale, J. Phys. Chem. C, 2015, 119, 28167-28181.

25. A. Abuteen, S. Zanganeh, J. Akhigbe, L.P. Samankumara, A. Aguirre, N. Biswal, M. Braune, A. Vollertsen, B. Röder, C. Brückner, Q. Zhu, Phys. Chem. Chem. Phys, 2013, 15, 18502-18509.

26. J. Jiang, S. Guo, X. Wang, L. Xu, Q. Li, X. Zhang, R. Soc. Open Sci., 2019, 6, 181199.

27. Y. Zhang, J.F. Lovell, Wiley Interdiscip. Rev.: Nanomed. Nanobiotechnol., 2017, 9, e1420.

28. K.S. Suslick, N.A. Rakow, M.E. Kosal, J.-H. Chou, J. Porphyrins Phthalocyanines, 2000, 4, 407-413. 
29. M. Harbeck, D.D. Erbahar, I. Gürol, E. Musluoğlu, V. Ahsen, Z.Z. Öztürk, Sensors and Actuators B:

Chemical, 2011, 155, 298-303.

30. C. Solis, E. Baigorria, M.E. Milanesio, G. Morales, E.N. Durantini, L. Otero, M. Gervaldo, Electrochim. Acta, 2016, 213, 594-605.

31. Z. Dai, Q. Sun, X. Liu, C. Bian, Q. Wu, S. Pan, L. Wang, X. Meng, F. Deng, F.-S. Xiao, J. Catal., 2016, 338, 202-209.

32. J. Jiang, S. Yoon, Sci. Rep., 2018, 8, 13243.

33. J. Zhang, L. Wang, C. Li, Y. Li, J. Liu, Y. Tu, W. Zhang, N. Zhou, X. Zhu, J. Polym. Sci. A, 2014, 52, 691-698.

34. P. Mashazi, C. Togo, J. Limson, T. Nyokong, J. Porphyrins Phthalocyanines, 2010, 14, 252-263.

35. H. Zhang, Y. Zhang, C. Gu, Y. Ma, Adv. Energy Mater., 2015, 5, 1402175.

36. W. Zhao, J. Peng, W. Wang, B. Jin, T. Chen, S. Liu, Q. Zhao, W. Huang, Small, 2019, 15, 1901351.

37. W. Zhao, W. Wang, J. Peng, T. Chen, B. Jin, S. Liu, W. Huang, Q. Zhao, Dalton Trans., 2019, 48, 9631-9638.

38. P.J. Dandliker, F. Diederich, M. Gross, C.B. Knobler, A. Louati, E.M. Sanford, Angew. Chem., Int. Ed. Engl., 1994, 33, 1739-1742.

39. S. Hecht, H. Ihre, J.M. Fréchet, J. Am. Chem. Soc., 1999, 121, 9239-9240.

40. N.T. Nguyen, J. Hofkens, I.G. Scheblykin, M. Kruk, W. Dehaen, Eur. J. Org. Chem., 2014, 8, 17661777.

41. U. Boas, J.B. Christensen, P.M.H. Heegaard, J. Mater. Chem., 2006, 16, 3785-3798.

42. M.B. Suarez, J. Durantini, L. Otero, T. Dittrich, M. Santo, M.E. Milanesio, E. Durantini, M. Gervaldo, Electrochim. Acta, 2014, 133, 399-406. 
43. A. Liddell, M. Gervaldo, J.W. Bridgewater, A.E. Keirstead, S. Lin, T.A. Moore, A.L. Moore, D. Gust, Chem. Mater., 2008, 20, 135-142.

44. J.Y. Lee, H.J. Song, S.M. Lee, J.H. Lee, D.K. Moon, Eur. Polym. J., 2011, 47, 1686-1693.

45. H. Zhou, X. Zhi, H-J. Zhai, Organic Electronics, 2018, 63, 149-158.

46. D. Heredia, L. Fernandez, L. Otero, M. Ichikawa, C.-Y. Lin, Y.-L. Liao, S.-A. Wang, K.-T. Wong, F. Fungo, J. Phys. Chem. C, 2011, 115, 21907-21914.

47. S.-H. Hsiao, J.-C. Hsueh, J. Electroanal. Chem., 2015, 758, 100-110.

48 L. Wang, J. Ding, S. Sun, B. Zhang, X. Tian, J. Zhu, S. Song, B. Liu, X. Zhuang, Y. Chen, Adv. Mater. Interfaces, 2018, 5, 1701679.

49 K. Jiang, I.A. Baburin, P. Han, C. Yang, X. Fu, Y. Yao, J. Li, E. Cánovas, G. Seifert, J. Chen, M. Bonn, X. Feng, X. Zhuang, Adv. Funct. Mater., 2020, 30, 1908243.

50. C. Maeda, S. Yamaguchi, C. Ikeda, H. Shinokubo, A. Osuka, Org. Lett., 2008, 10, 549-552.

51. D.A. Roberts, T.W. Schmidt, M.J. Crossley, S. Perrier, Chem. Eur. J., 2013, 19, 12759-12770.

52. G. de Miguel, M. Wielopolski, D.I. Schuster, M.A. Fazio, O.P. Lee, C.K. Haley, A.L. Ortiz, L. Echegoyen, T. Clark, D.M. Guldi, J. Am. Chem. Soc., 2011, 133, 13036-13054.

53. A. Eggenspiller, A. Takai, M.E. El-Khouly, K. Ohkubo, C.P. Gros, C. Bernhard, C. Goze, F. Denat, J.-M. Barbe, S. Fukuzumi, J. Phys. Chem. A, 2012, 116, 3889-3898.

54 P. Zhang, F. Zhu, F. Wang, J. Wang, R. Dong, X. Zhuang, O. G. Schmidt, X. Feng. Adv. Mater, 2017, 29, 1604491.

55 C. Zheng, J. Zhu, C. Yang, C. Lu, Z. Chen, X. Zhuang, Sci. China Chem., 2019, 62, 1145-1193.

56 J. Zhu, C. Yang, C. Lu, F. Zhang, Z. Yuan, X. Zhuang, Acc. Chem. Res., 2019, 51, 3191-3202. 
57 D. Zhao, W. Chang, C. Lu, C. Yang, K. Jiang, X. Chang, H. Lin, F. Zhang, S. Han, Z. Hou, X. Zhuang, Small, 2019, 15, 1901494.

58 D. Zhao, K. Jiang, J. Li, X. Zhu, C. Ke, S. Han, E. Kymakis, X. Zhuang. BMC Mat., 2020, $2,3$.

59. H. Zhou, H-J. Zhai, Organic Electronics, 2016, 37, 197-206.

60. J. Miao, X. Dong, Y. Xu, Z. Zhai, L. Zhang, B. Ren, Z. Liu, Organic Electronics, 2019, 73, 304-310

61. S. Zhang, J. Ren, Y. Zhang, H. Peng, S. Chen, F. Yang, Y. Cao, Organic Electronics, 2019 art. no. 105497

62. D. Heredia, S.R. Martínez, A.M. Durantini, M.E. Pérez, M.I. Mangione, J.E. Durantini, M. Gervaldo, L.A. Otero, E.N. Durantini, ACS Appl. Mater. Interfaces, 2019, 11, 27574-27587.

63. A. Yu, V. Chabot, J. Zhang. Electrochemical Supercapacitors for Energy Storage and Delivery: Fundamentals and Applications, CRC Press, 2017.

64. S. Zang, N. Pan, Adv. Energy Mat. 2015, 5, 1401401.

65. C. J. Raj, M. R. Ramu, M. S. Park, J. H. Park, K. H. Yu, B. C. Kim, Ionics, 2018, 24, 2335-2342.

66. C. J. Raj, B. Chul Kim, W-J Cho, W-G Lee, S-D Jung, Y. H. Kim, S. Y. Park, K. H. Yu, ACS Appl. Mater. Interfaces, 2015, 7, 13405-13414.

67. D. Dolphin, The Porphyrins, $1^{\text {st }}$ Edition ed., Elsevier, Academic Press, 1978.

68. A.J. Bard, L.R. Faulkner, J. Leddy, C.G. Zoski, Electrochemical methods: fundamentals and applications, Wiley New York, 1980.

69. J.F. Ambrose, R.F. Nelson, J. Electrochem. Soc., 1968, 115, 1159-1164.

70. P. Pander, A. Swist, P. Zassowski, J. Soloducho, M. Lapkowski, P. Data, Electrochim. Acta, 2017, 257, 192-202.

71. S.-H. Hsiao, J.-W. Lin, Macromol. Chem. Phys., 2014, 215, 1525-1532. 
72. H. Imahori, S. Kang, H. Hayashi, M. Haruta, H. Kurata, S. Isoda, S.E. Canton, Y. Infahsaeng, A.

Kathiravan, T. Pascher, P. Chábera, A.P. Yartsev, V. Sundström, J. Phys. Chem. A, 2011, 115, 3679-3690.

73. H. Imahori, K. Tamaki, Y. Araki, Y. Sekiguchi, O. Ito, Y. Sakata, S. Fukuzumi, J. Am. Chem. Soc., 2002, 124, 5165-5174.

74 J. Durantini, L. Otero, M. Funes, E.N. Durantini, F. Fungo, M. Gervaldo, Electrochim. Acta, 2011, 56, 4126-4134.

75. Z.J. Zhang, D.H. Xie, P. Cui, X.Y. Chen, RSC Adv., 2014, 4, 6664-6671.

76. M.M. Pérez-Madrigal, F. Estrany, E. Armelin, D.D. Díaz, C. Alemán, J. Mater. Chem. A, 2016, 4, 1792-1805.

77. C. Lei, F. Markoulidis, Z. Ashitaka, C. Lekakou, Electrochim. Acta, 2013, 92, 183-187.

78. S.-M. Chen, R. Ramachandran, V. Mani, R. Saraswathi, Int. J. Electrochem. Sci, 2014, 9, 4072-4085.

79. T.-H. Le, Y. Kim, H. Yoon, Polymers, 2017, 9, 150.

80. H. Zhang, M. Yao, J. Wei, Y. Zhang, S. Zhang, Y. Gao, J. Li, P. Lu, B. Yang, Y. Ma, Adv. Energy Mater., 2017, 7, 1701063. 


\section{Figure captions}

Figure 1. Chemical structure of the studied molecules. a). P, b) D, and c) PD.

Figure 2. First anodic cyclic voltammetric scans of: a). P, b) D, and c) PD. Pt electrode, scan rate $100 \mathrm{mV}$ $\mathrm{s}^{-1}$. Differential pulse voltammograms of: d) $\mathbf{P}, \mathbf{D}$, and PD. Pt electrode, scan rate $25 \mathrm{mV} \mathrm{s}^{-1}$. All measurements were conducted in DCE containing 0.10 $\mathrm{M} \mathrm{TBAPF}_{6}$.

Figure 3. Ten consecutive cyclic voltammetric scans of: a). D, b) PD. Pt electrode, scan rate $100 \mathrm{mV} \mathrm{s}^{-1}$. Voltammetric responses of: c) D-film, d) PD-film over Pt electrode at different scan rates. DCE containing only supporting electrolyte $\left(0.10 \mathrm{M} \mathrm{TBAPF}_{6}\right)$.

Figure 4. a) Ten consecutive cyclic voltammetric scans of PD on ITO electrode, scan rate $100 \mathrm{mV} \mathrm{s}^{-1}$. b) Voltammetric response of PD-film on ITO electrode, scan rate $100 \mathrm{mV} \mathrm{s}^{-1}$. c) Anodic and cathodic peak currents vs scan rate for PD-film on ITO electrode. d) Cyclic voltammograms after five, ten, and fifty repetitive cycles. All measurements were conducted in DCE $\left(0.10 \mathrm{M} \mathrm{TBAPF}_{6}\right)$.

Figure 5. Difference absorption spectra of: a) D-film and b) PD-film, deposited on ITO electrodes. Changes in the principal absorption traces of: c) D-film and d) PD-film, deposited on ITO electrodes. Insets: Absorption spectra of: a) D-film, b) PD-film, deposited on ITO electrodes.

Figure 6. Photographic Images of PD-film on ITO showing the colors of the different oxidized states.

Figure 7. SEM images of a) D-film and b) PD-film. Scale bars are $300 \mathrm{~nm}$. 
Figure 8. AFM topographic images of PD-film on ITO after a) 2, b) 4 and c) 17 polymerization cycles.

Figure 9: a) Electrochemical response of a PD-film in $\mathrm{ACN}(0.10 \mathrm{M}$ TBAP) after 1, 10, and 50 repetitive cycles (scan rate $\left.100 \mathrm{mV} \mathrm{s}^{-1}\right)$. The film was deposited by ten polymerization cycles in DCE $(0.10 \mathrm{M}$ $\left.\mathrm{TBAPF}_{6}\right)$. b) Anodic and cathodic peak currents vs scan rate for PD-film on ITO electrode in ACN $(0.10$ M TBAP).

Figure 10. a) Galvanostatic charge/discharge cycles of PD-film at different current densities. b) Cycling stability of PD-film at 18.2 $\mathrm{A} \mathrm{g}^{-1}$. (c) Capacitance retention \% of PD-film. d) Nyquist plot of PD-film at 1.1 V. The PD-film was deposited on an ITO electrode. All measurements were conducted in ACN containing 0.10 M TBAP.

Figure 11. Proposed chemical structure of PD-film. 


\section{Figure 1}

(a)

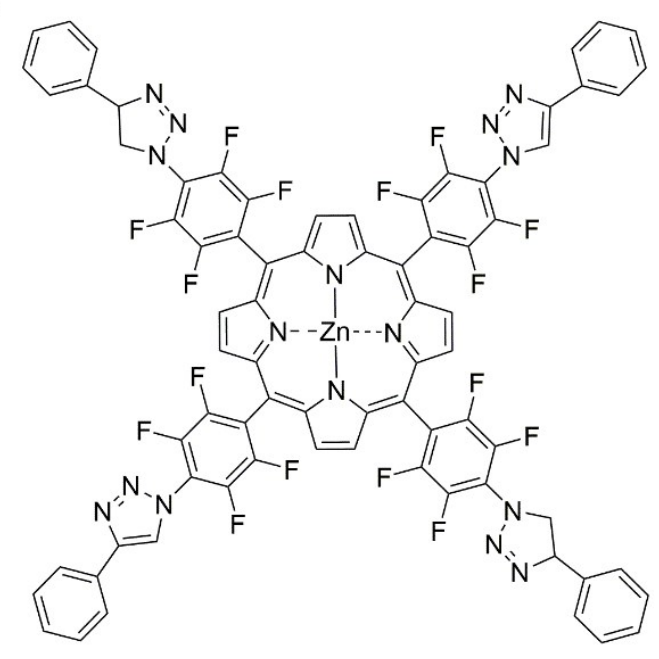

(b)

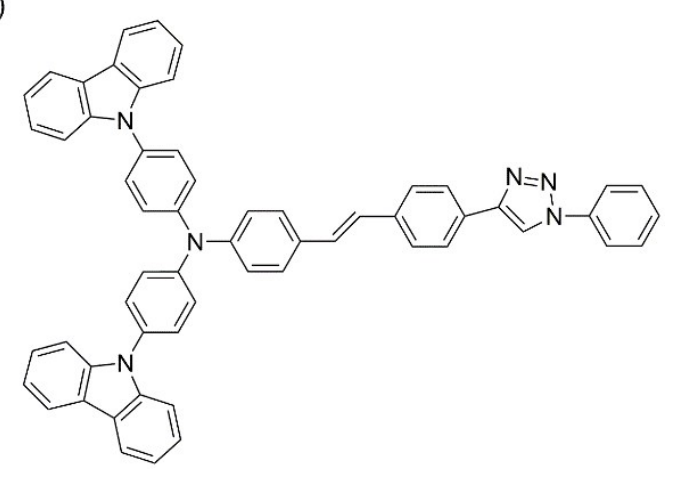

(c)

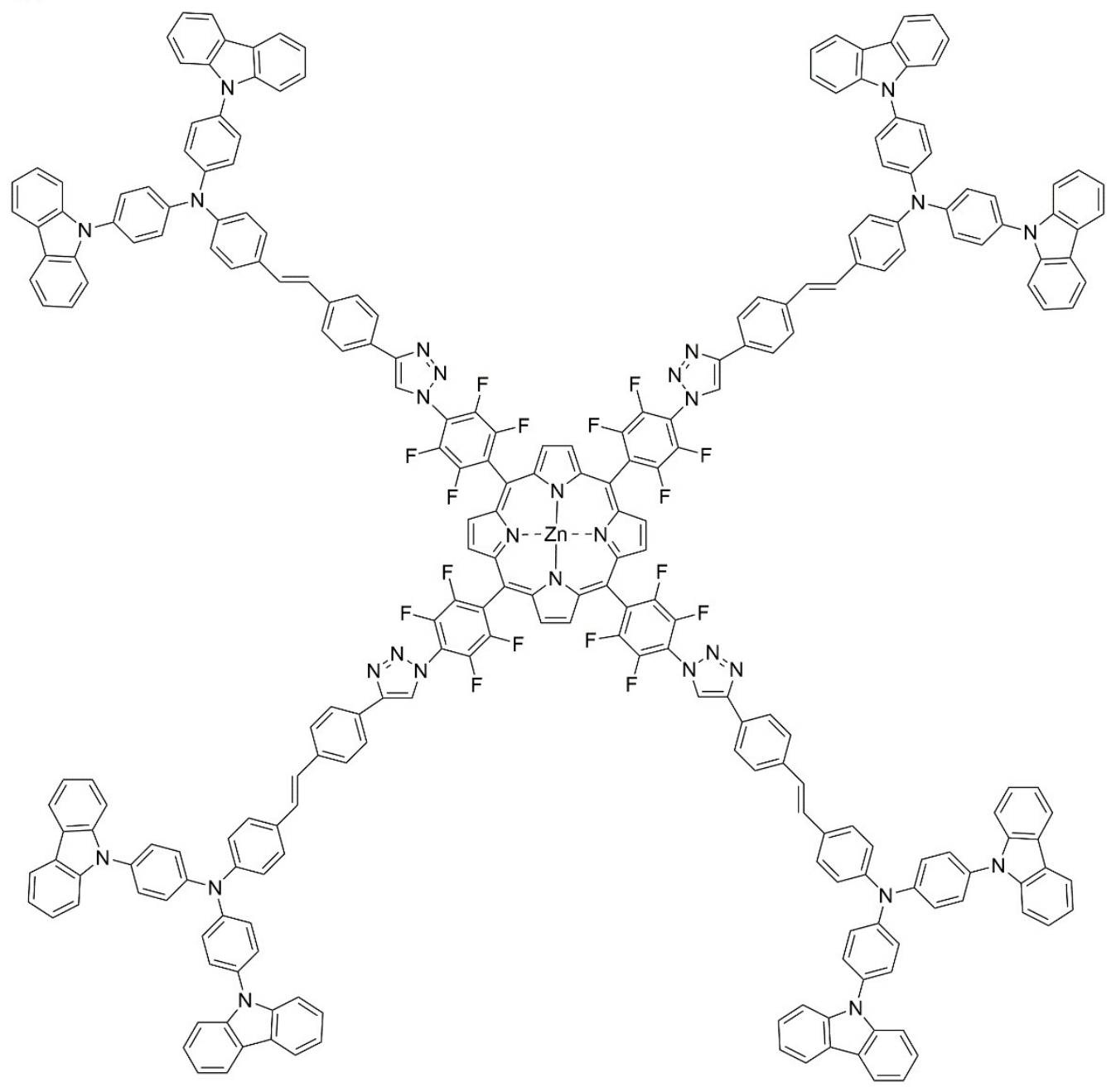




\section{Figure 2}
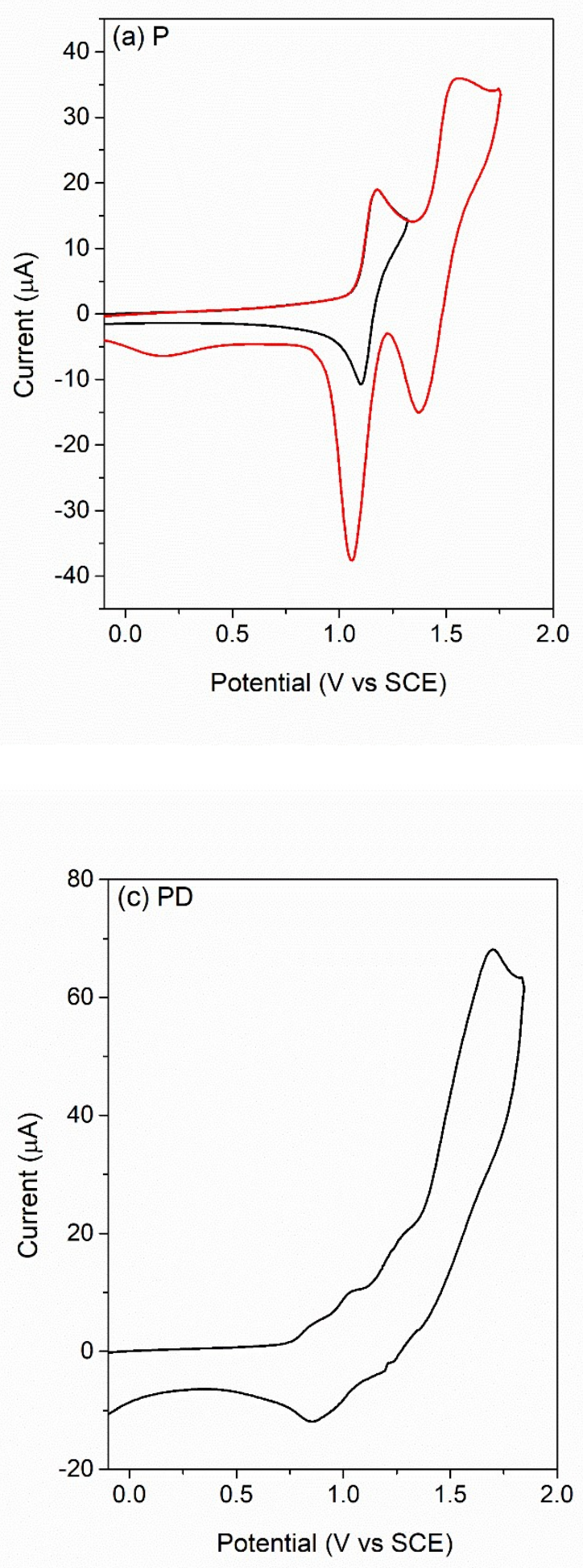
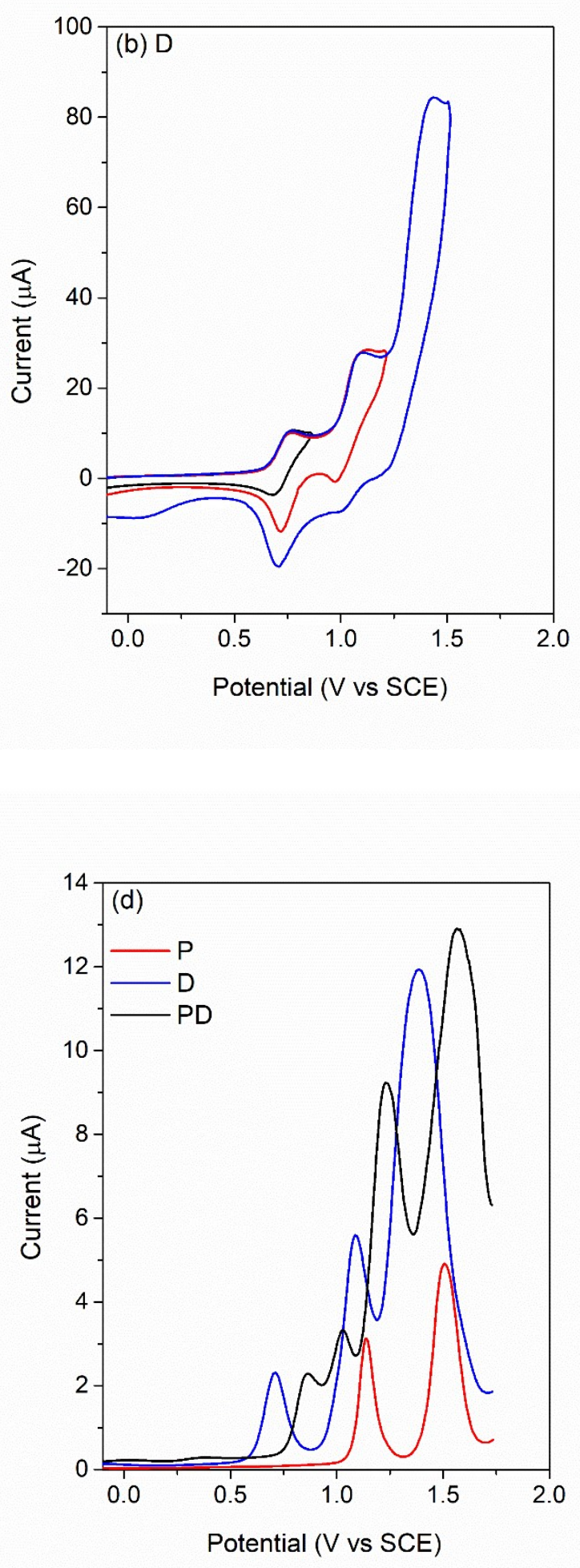


\section{Figure 3}
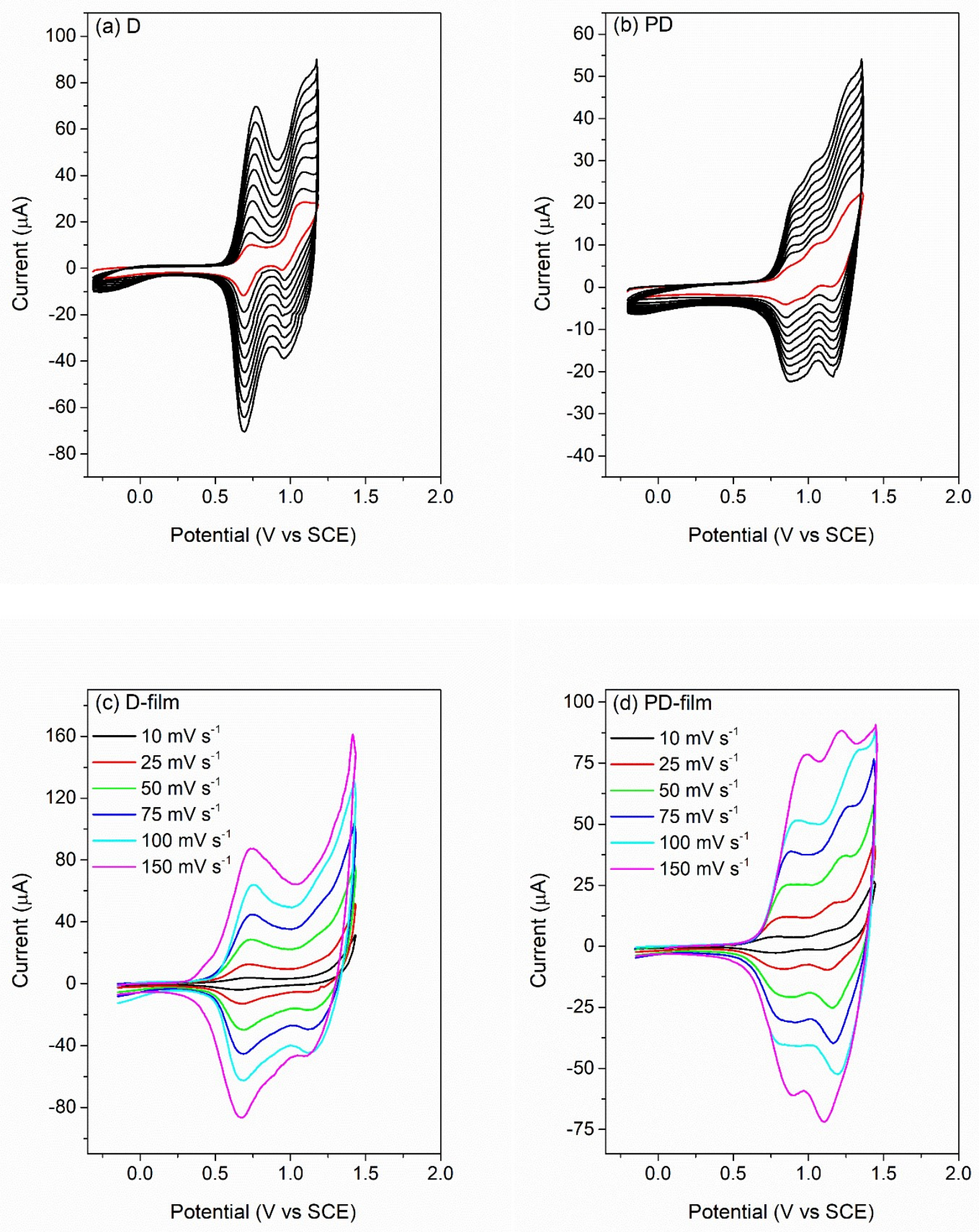


\section{Figure 4}
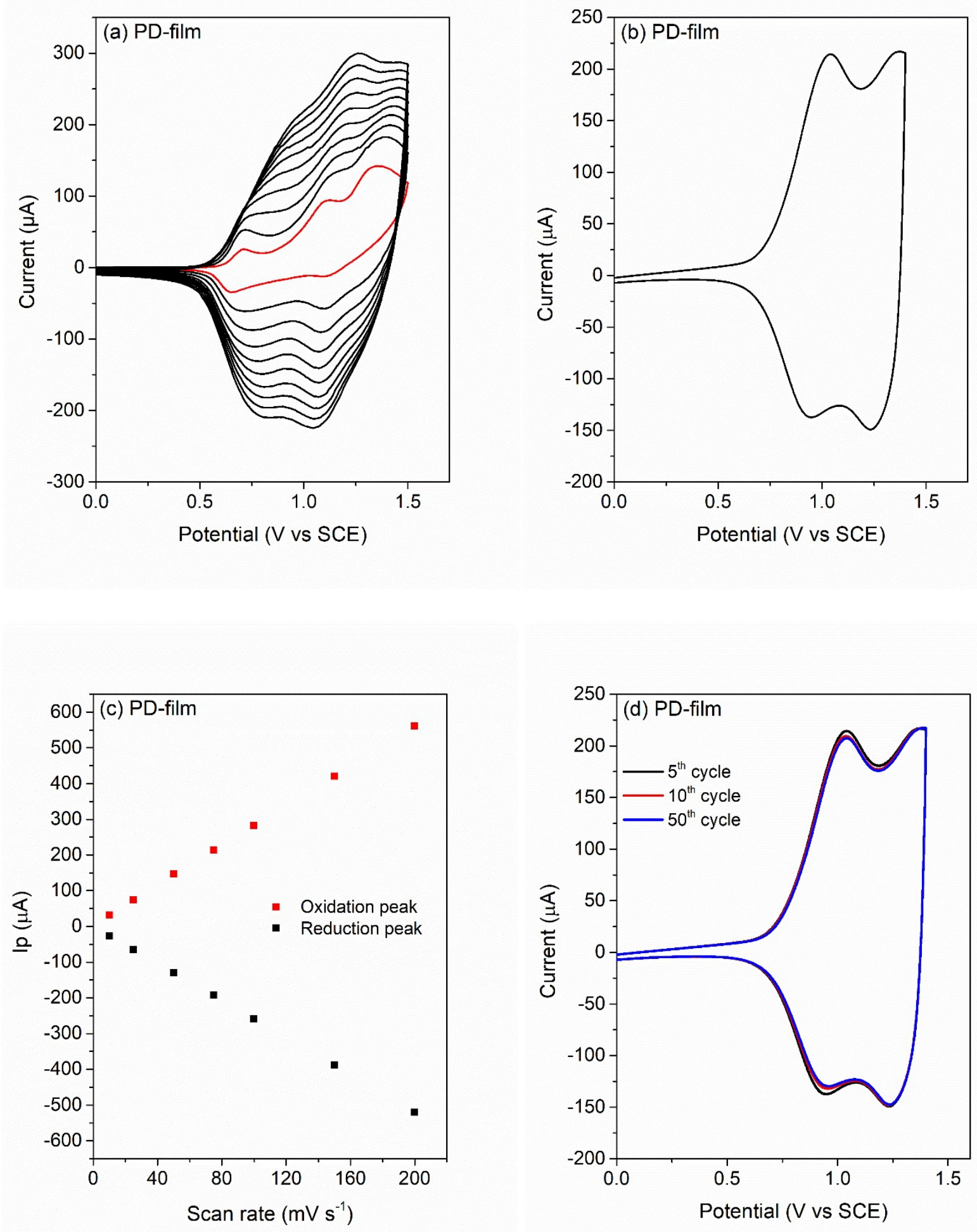


\section{Figure 5}
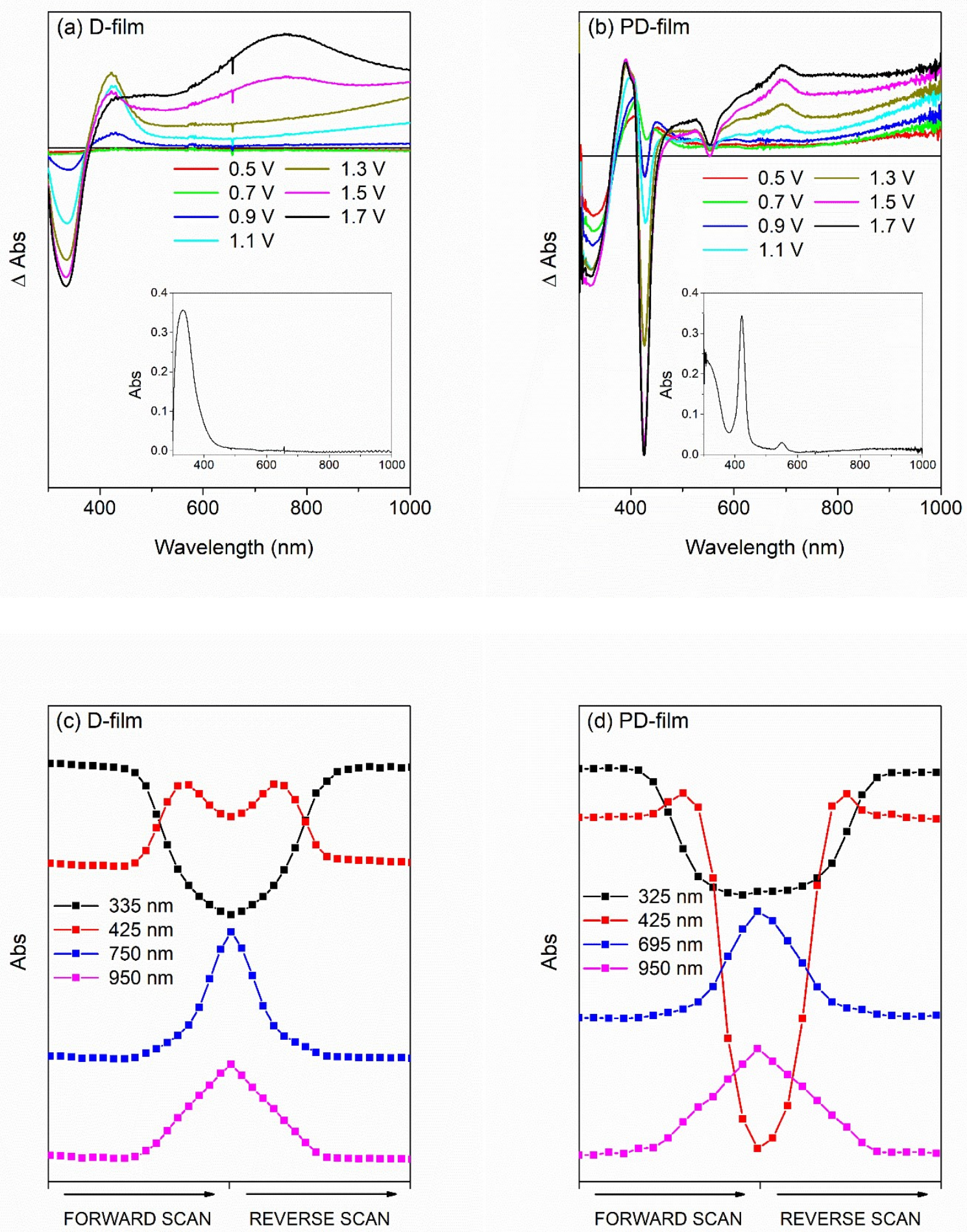


\section{Figure 6}

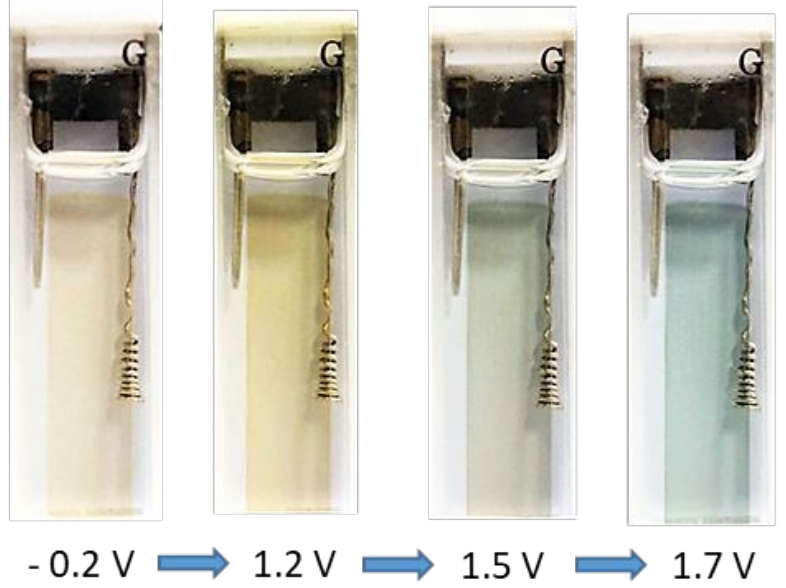




\section{Figure 7}
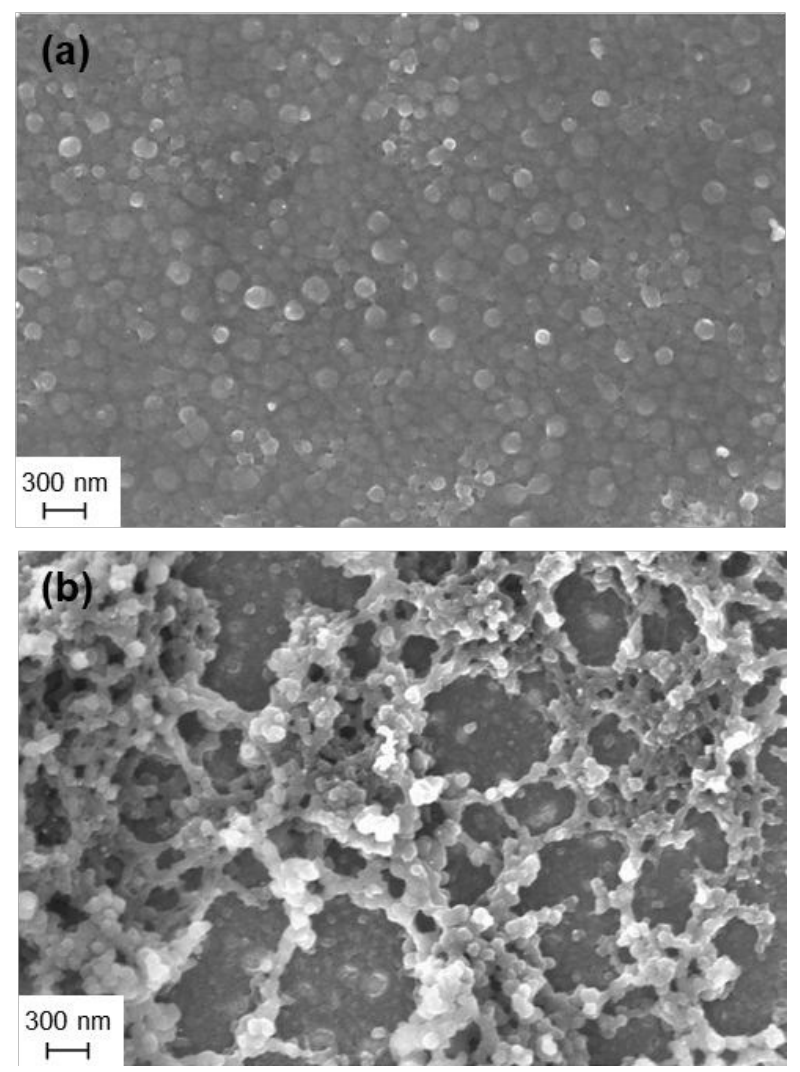


\section{Figure 8}
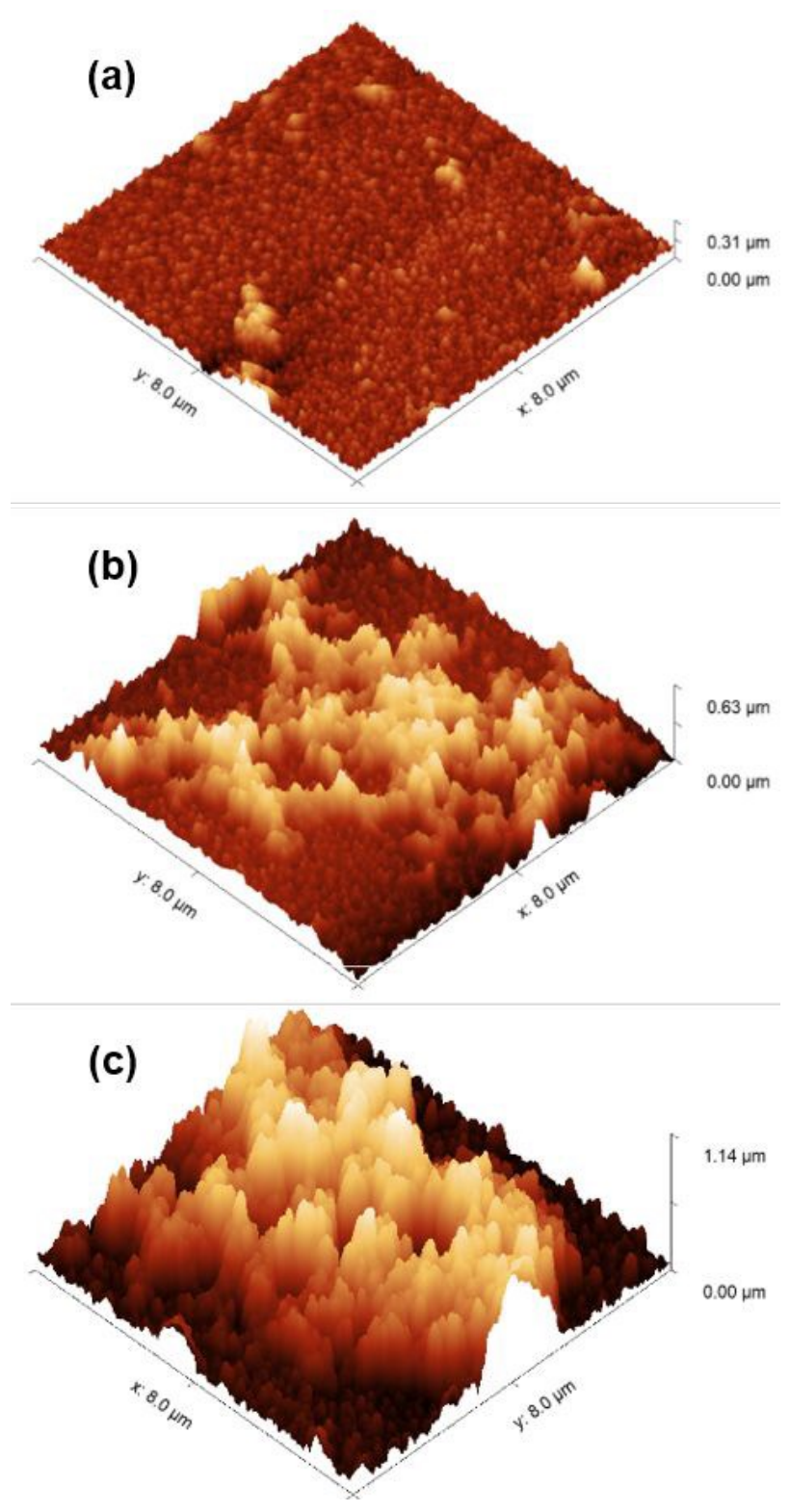


\section{Figure 9}
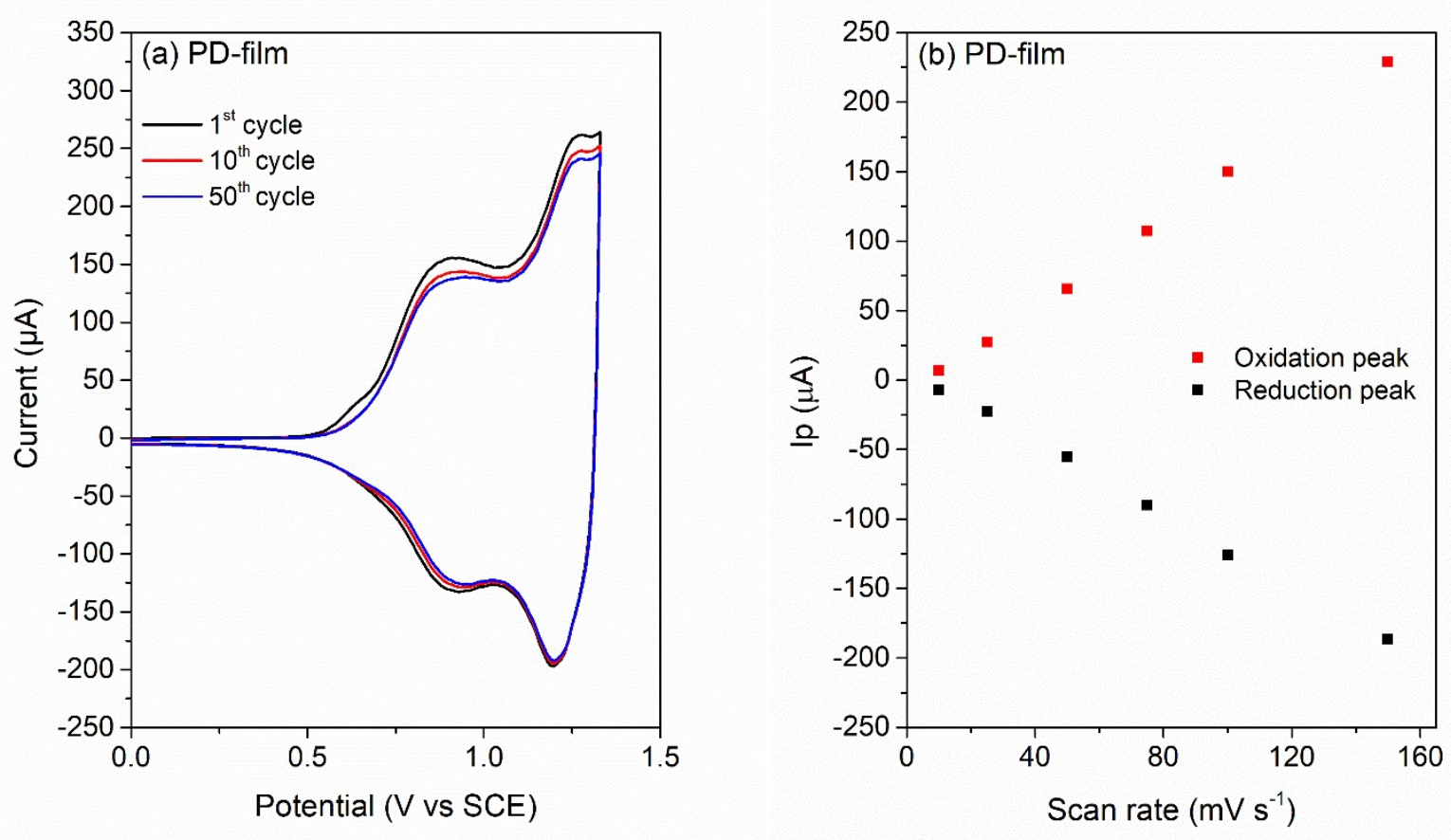
Figure 10
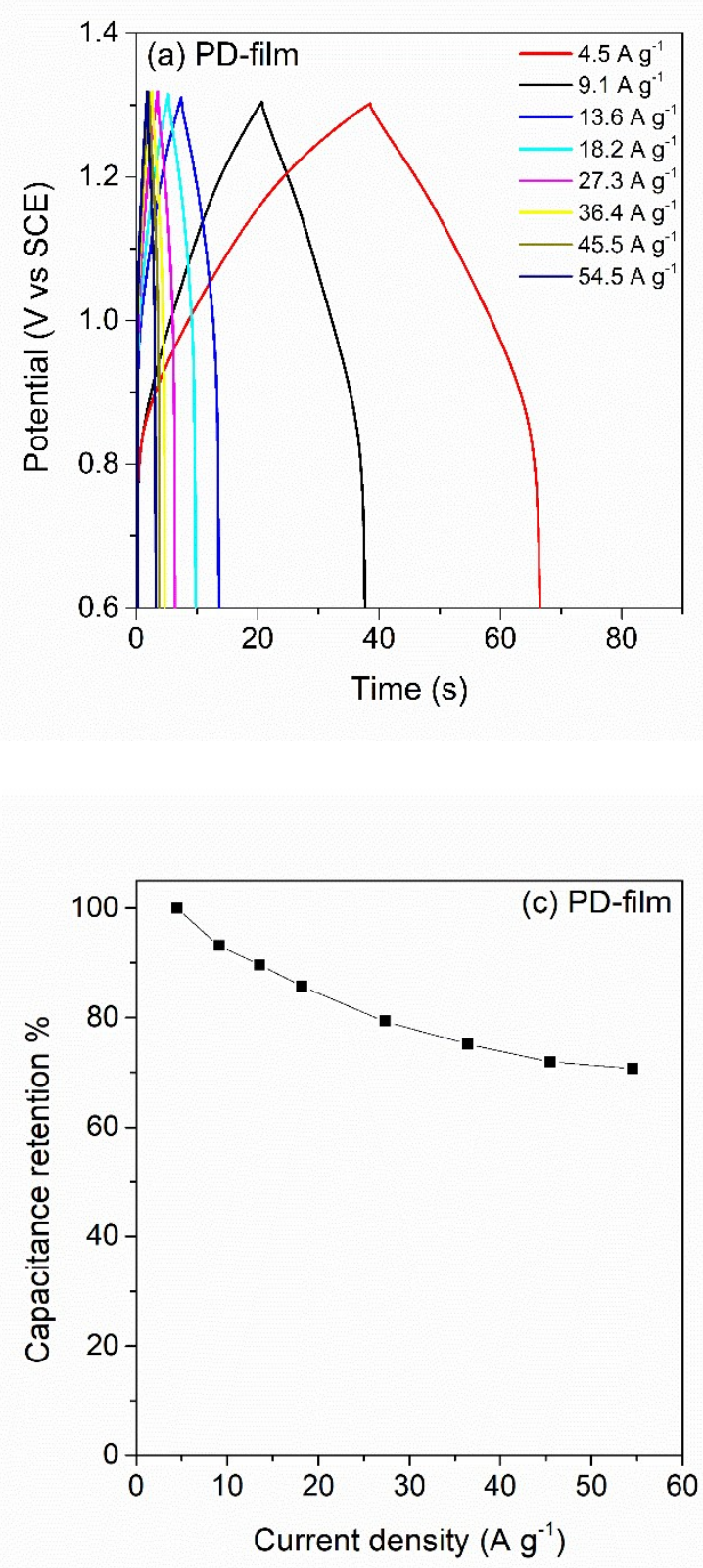
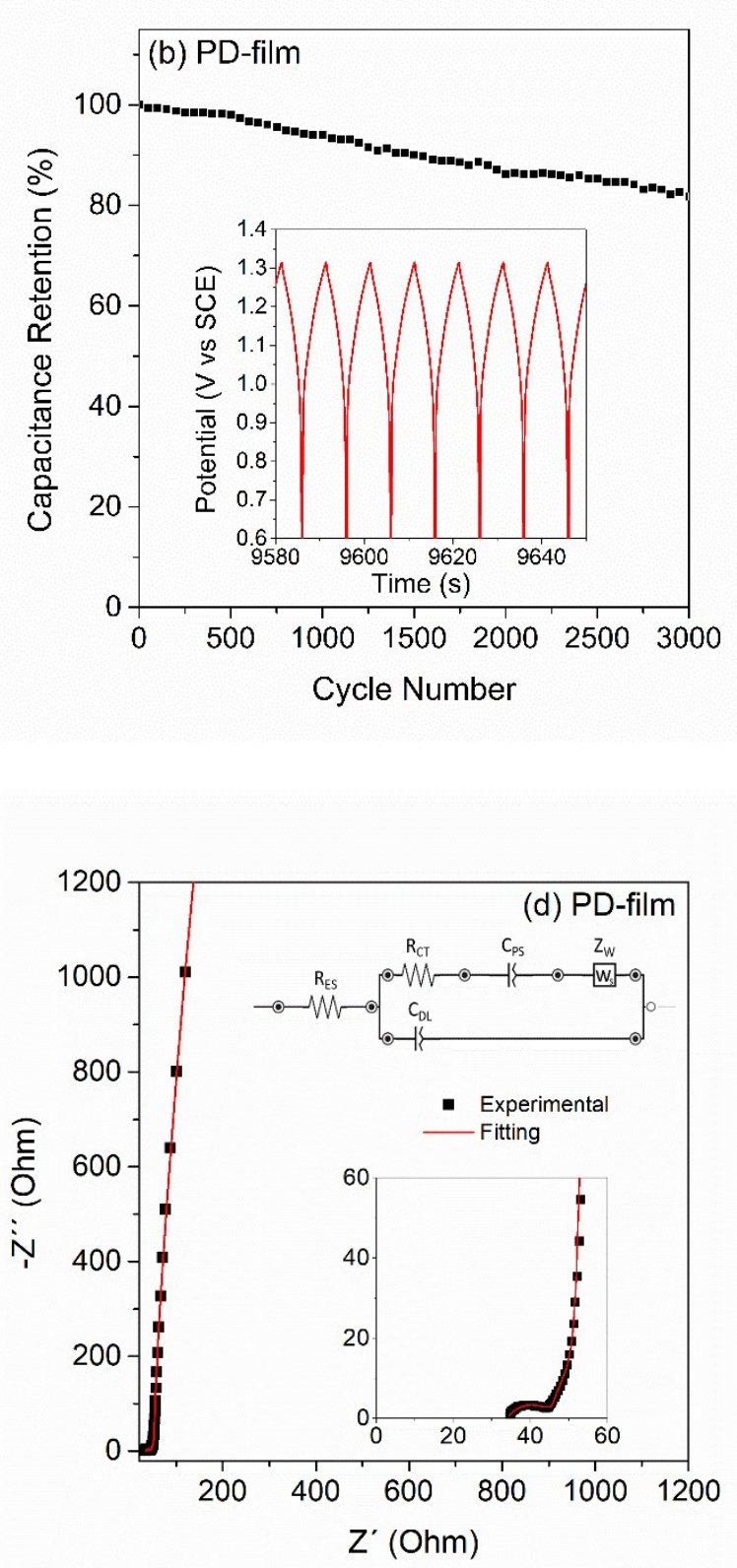


\section{Figure 11}

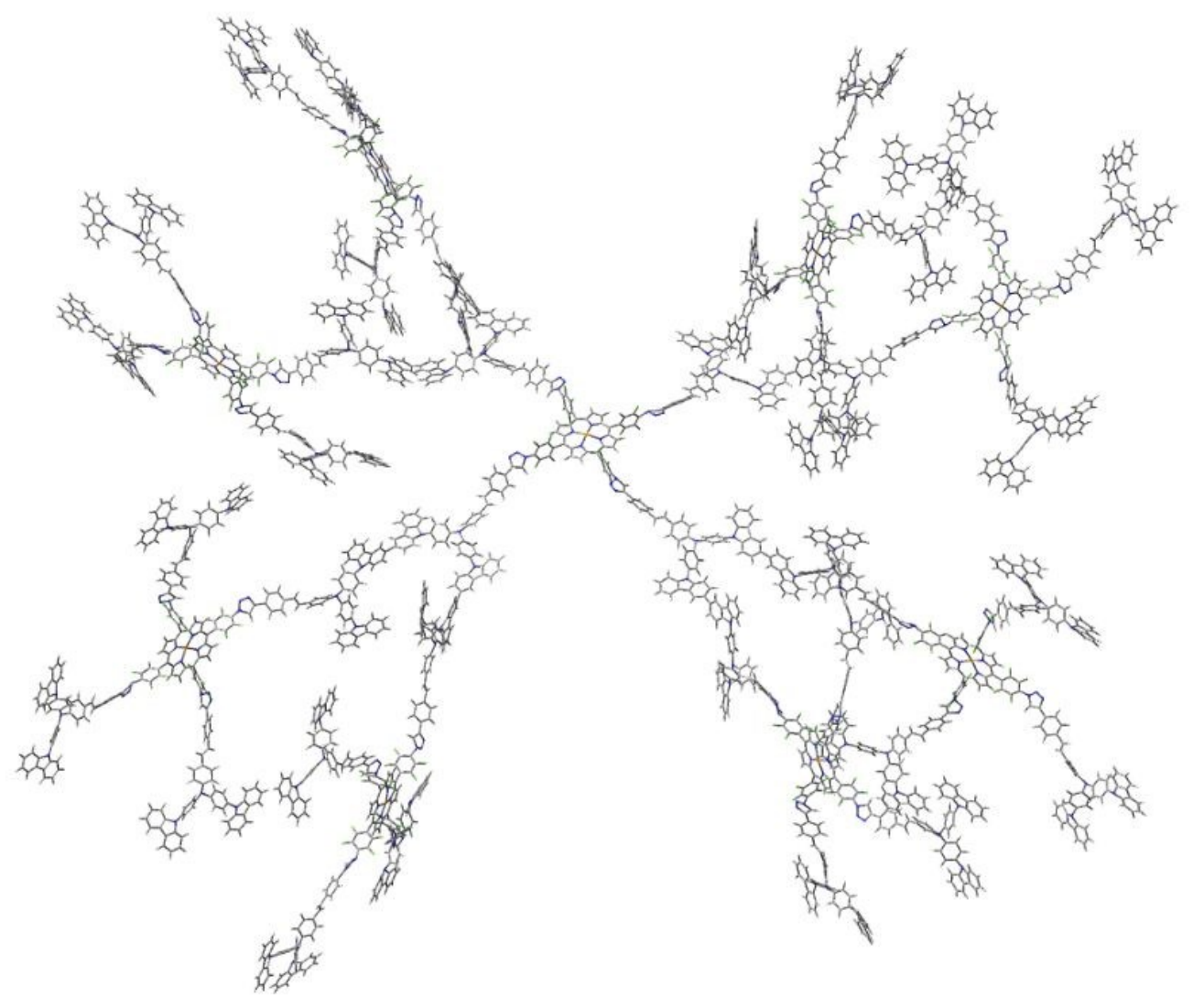




\section{Graphical abstract description}

A hyperbranched polymeric conducting film was generated by electrochemical polymerization of a $\mathrm{Zn}$ (II) porphyrin monomer. The polymer presents adequate electronic properties for applications in electrochromic and energy storage devices.

\section{Graphical abstract}

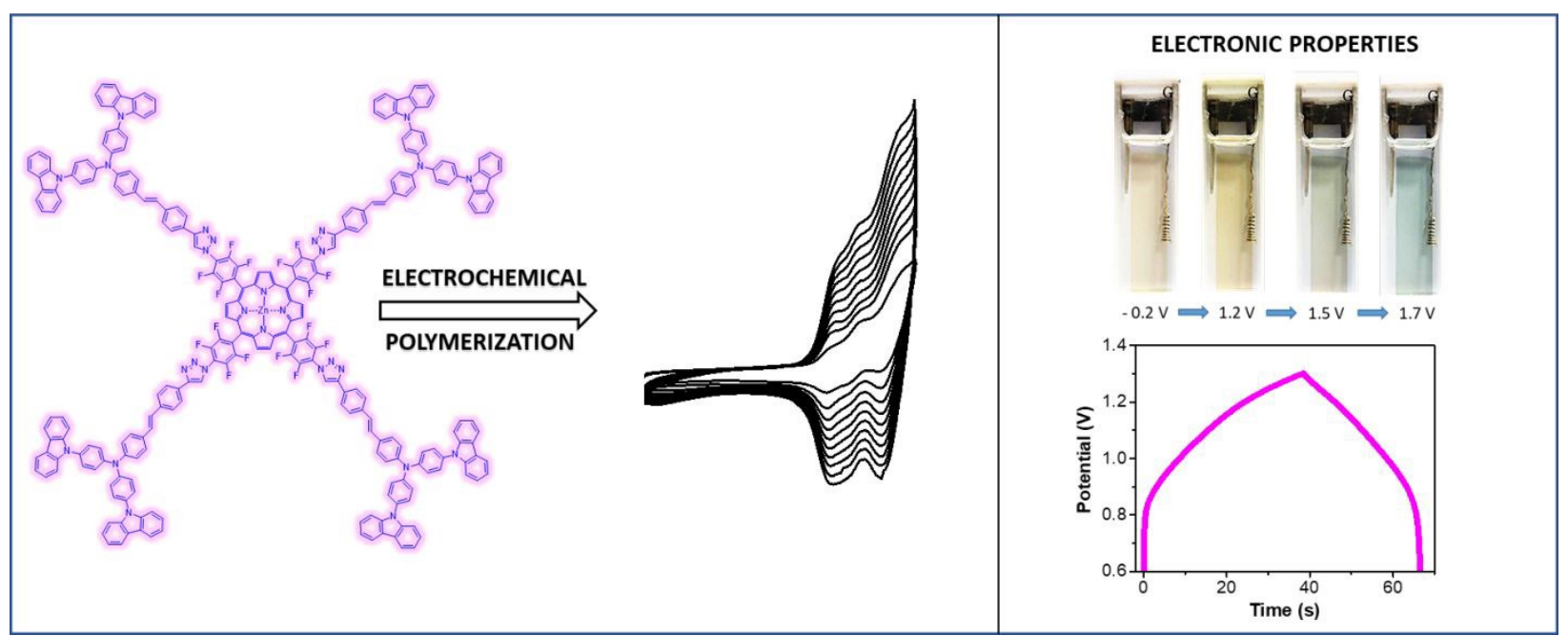

